\title{
Paradoxical increase of pulmonary vascular resistance during testing of inhaled iloprost
}

\author{
M Emmel, B Keuth, S Schickendantz
}

Heart 2003;90:e2 (http://www.archdischild.com/cgi/content/full/90/1/e2)

The case of a 14 month old girl with primary pulmonary hypertension treated with domiciliary oxygen is described. After invasive evaluation and testing of nitric oxide with very good response, the testing was repeated to study the effect of inhaled iloprost on pulmonary vascular resistance (PVR). An unexpected and severe increase of PVR was observed, rising from 392 dynes $\cdot \mathrm{s} \cdot \mathrm{cm}^{-5}$ with oxygen to a maximum of 1192 dynes $\cdot \mathrm{s} \cdot \mathrm{cm}^{-5}$ with oxygen and iloprost. Underlying ventilatory and technical problems were excluded. While inhaled iloprost has been described to be highly effective in the treatment of primary pulmonary hypertension, the possibility of contrary "paradoxical" reactions in isolated patients is emphasised, with a dramatic increase of PVR and a possible adverse outcome.

A n 8 month old white infant (weight $4.4 \mathrm{~kg}$ ) presented with tachypnoea and severe failure to thrive. Transthoracic Doppler echocardiogram estimated a systolic right ventricular pressure of $70 \mathrm{~mm} \mathrm{Hg}$ in room air, decreasing to $40 \mathrm{~mm} \mathrm{Hg}$ with oxygen. Underlying disorders of the respiratory system, obstructive sleep apnoea, portal hypertension, thromboembolic diseases, HIV infection, and collagen vascular diseases were excluded.

Cardiac catheterisation was performed to test the effect of pulmonary vasodilator agents. After premedication with intramuscular pentobarbital, morphine, and scopolamine, right and left heart catheterisation was performed under local anaesthesia with the patient breathing spontaneously. Complete measurements were made first in room air, then with oxygen administration (fractional inspired oxygen 1.0). Heart rate and vascular pressures were measured continuously. Cardiac output was measured by Fick's principle. Vascular resistances were calculated from mean vascular and atrial pressures.

The diagnosis of primary pulmonary hypertension (PPH) was confirmed. An increased mean pulmonary artery pressure (mPAP) of $33 \mathrm{~mm} \mathrm{Hg} \mathrm{(41 \%} \mathrm{of} \mathrm{mean} \mathrm{systemic} \mathrm{artery}$ pressure (mSAP)) was measured in room air and pulmonary vascular resistance (PVR) was 880 dynes $\cdot \mathrm{s}^{\cdot} \mathrm{cm}^{-5}(44 \%$ of systemic artery resistance). After 10 minutes of oxygen administration mPAP decreased to $23 \mathrm{~mm} \mathrm{Hg}$ (32\% mSAP) and PVR to 400 dynes $\cdot s \cdot \mathrm{cm}^{-5}(27 \%$ systemic vascular resistance). In view of the good response to oxygen, the patient was treated with domiciliary nocturnal oxygen in the next six months.

Because of a lack of clinical improvement cardiac catheterisation was repeated at the age of 14 months to explore the therapeutic effect of nitric oxide and inhaled iloprost. After endotracheal intubation the patient was sedated with pentobarbital. Mechanical ventilation was performed with a Servo 300 (Siemens, Munich, Germany). Normal oxygen uptake was measured with a Deltatrac II
(Datex Engstrom, Helsinki, Finland). Normocapnia was verified by repeated arterial blood gas analysis. $\mathrm{CO}_{2}$ partial pressure range was 31 to $44 \mathrm{~mm} \mathrm{Hg}$. Catheterisation confirmed highly increased pulmonary artery pressure and PVR in room air (table 1), decreasing after 10 minutes of oxygen administration. Subsequently, the effect of nitric oxide $(20 \mathrm{ppm})$ in combination with oxygen was tested over a period of 20 minutes. The response was excellent, with physiological pressure and resistance levels being achieved. After termination of nitric oxide application, testing of inhaled iloprost (Schering, Berlin, Germany) was started after a 10 minute ventilation with oxygen alone. We used the ultrasonic nebuliser Optineb (Nebu-Tec, Elsenfeld, Germany), compatible with Servo 300, which produces an aerosol with a particle diameter between 3-5 $\mu \mathrm{m}$. Iloprost was administrated in repeated dosages of $0.2 \mu \mathrm{g} / \mathrm{kg}$ dissolved into a physiological sodium chloride solution, inhaled over a period of 10 minutes each, while continuing oxygen ventilation. A steady rise in MPAP was noted, and mSAP and the cardiac index appeared to be in steady state. Oxygen uptake, arterial oxygen saturation and partial carbon dioxide pressure remained unchanged. The patient did not awaken and no pentobarbital was administered during this part of the testing schedule. Testing was stopped after the third iloprost dose with an actual cumulative dosage of $0.6 \mu \mathrm{g} / \mathrm{kg}$ because of alarmingly increased levels of mPAP and PVR, reaching nearly systemic values. Table 1 shows the changes in the most important parameters during testing. Each value is the maximum achieved.

Cardiac catheterisation was repeated after a short interval. Invasive testing with nifedipine had a beneficial effect on mPAP and PVR without negative side effects on mSAP and the cardiac index. Oral long term treatment with nifedipine was started.

\section{DISCUSSION}

$\mathrm{PPH}$ is an incurable disease with poor prognosis. ${ }^{1}$ Because causal treatment of $\mathrm{PPH}$ is impossible, symptomatic treatment is necessary and should result in decreased PVR, improved clinical and symptomatic findings, and prolonged survival. ${ }^{23}$ Agents that have been used include supplemental oxygen, anticoagulants, calcium channel antagonists, inhaled nitric oxide as a testing agent, epoprostenol (central venous application), and beraprost as a stable prostaglandin $I_{2}$ analogue administered orally. ${ }^{2-8}$

Inhaled doses of iloprost, a stable prostaglandin $\mathrm{I}_{2}$ derivative, have been shown to have beneficial effects on adults and children with PPH without severe local or

Abbreviations: mPAP, mean pulmonary artery pressure; mSAP, mean systemic artery pressure; PPH, primary pulmonary hypertension; PVR, pulmonary vascular resistance 
Table 1 Maximum levels of mPAP, PVR, and cardiac index during testing

\begin{tabular}{lllll}
\hline Parameter/condition & Room air & Oxygen & $\begin{array}{l}\text { Nitric oxide }+ \\
\text { oxygen }\end{array}$ & $\begin{array}{l}\text { lloprost }+ \\
\text { oxygen }\end{array}$ \\
\hline mPAP $(\mathrm{mm} \mathrm{Hg})(\% \mathrm{mSAP})$ & $48(59)$ & $28(37)$ & $21(25)$ & $61(79)$ \\
PVR $\left(\right.$ dynes $\left.\cdot \mathrm{s} \cdot \mathrm{cm}^{-5}\right)(\% \mathrm{SVR})$ & $856(51)$ & $392(27)$ & $232(14)$ & $1192(79)$ \\
Cardiac index $\left(\mathrm{l} / \mathrm{min} / \mathrm{m}^{2}\right)$ & 3.73 & 3.89 & 3.81 & 3.76 \\
\hline
\end{tabular}

mPAP, mean pulmonary artery pressure; mSAP, mean systemic artery pressure; PVR, pulmonary vascular resistance; SVR, systemic vascular resistance

systemic side effects. ${ }^{10}$ We emphasise the possibility of adverse "paradoxical" reactions in isolated patients with a dramatic increase of pulmonary artery resistance and potential harmful outcome. Iloprostin is a prostanoid, which activates the prostacyclin receptor with a subsequent rise in intracellular cyclic AMP. Normally, a rise in cyclic AMP concentrations produces vasodilatation by relaxing smooth muscle cells. In our patient this cascade may have been altered, with the possibility that another prostanoid receptor was activated or that intracellular mechanisms different from that described above were activated.

Because this paradoxical reaction cannot be predicted, invasive diagnostic evaluation is obligatory.

\section{Authors' affiliations \\ M Emmel, B Keuth, S Schickendantz, University of Cologne, Cologne, Germany}

Correspondence to: Dr med M Emmel, Josef Stelzmann Strasse 9,50924 Cologne, Germany; mathias.emmel@medizin.uni-koeln.de

Accepted 2 July 2003

\section{REFERENCES}

1 Sandoval J, Bauerie O, Gomez A, et al. Primary pulmonary hypertension in children: clinical characterization and survival. $J$ Am Coll Cardiol 1995;25:466-74

2 Simon J, Gibbs R. Recommendations on the management of pulmonary hypertension in clinical practice. Heart 2001;86(suppl I):i1-13.

3 Klings ES, Farber HW. Current management of primary pulmonary hypertension. Drugs 2001;61:1945-56.

4 Wilkins MR, Wharton J. Progress in, and future prospects for, the treatment of primary pulmonary hypertension. Heart 2001;86:603-4.

5 Rich S, Brundage BH. High dose calcium channel-blocking therapy for primary pulmonary hypertension: evidence of long-term reduction in pulmonary arterial pressure and regression of right ventricular hypertrophy. Circulation 1987;76:135-41.

6 Sitbon O, Humbert M, Jagot JL, et al. Inhaled nitric oxide as a screening agent for safely identifying responders to oral calcium-channel blockers in primary pulmonary hypertension. Eur Respir J 1998;12:265-70.

7 Galié N, Manes A, Branzi A. Medical therapy of pulmonary hypertension: the prostacyclins. Clin Chest Med 2001;22:529-37.

8 Vizza CD, Sciomer S, Morelli S, et al. Long term treatment of pulmonary arterial hypertension with beraprost, an oral prostacyclin analogue. Heart 2001;86:661-5.

9 Channick RN, Rubin $\amalg$. New and experimental therapies for pulmonary hypertension. Clin Chest Med 2001;22:539-45.

10 Beghetti M, Berner M, Rimensberger PC. Long term inhalation of iloprost in a child with primary pulmonary hypertension: an alternative to continuous infusion. Heart 2001;86:e10. 